\title{
Non-Coding RNAs: New Players in Skin Wound Healing
}

\author{
Eva K. Herter* and Ning Xu Landén* \\ Unit of Dermatology and Venereology, Molecular Dermatology Research Group, Department of Medicine \\ Center for Molecular Medicine (CMM), Karolinska Institutet, Stockholm, Sweden.
}

Significance: Wound healing is a basic physiological process that is utilized to keep the integrity of the skin. Impaired wound repair, such as chronic wounds and pathological scars, presents a major health and economic burden worldwide. To date, efficient targeted treatment for these wound disorders is still lacking, which is largely due to our limited understanding of the biological mechanisms underlying these diseases. Research driven around discovering new therapies for these complications is, therefore, an urgent need.

Recent Advances: The vast majority of the human genome is transcribed to RNAs that lack protein-coding capacity. Intensive research in the recent decade has revealed that these non-coding RNAs (ncRNAs) function as important regulators of cellular physiology and pathology, which makes them promising therapeutic and diagnostic entities.

Critical Issues: A class of short ncRNAs, microRNAs, has been found to be indispensable for all the phases of skin wound healing and plays important roles in the pathogenesis of wound complications. The role of long ncRNAs (lncRNA) in skin wound healing remains largely unexplored. Recent studies revealed the essential role of lncRNAs in epidermal differentiation and stress response, indicating their potential importance for skin wound healing, which warrants future research.

Future Directions: An investigation of ncRNAs will add new layers of complexity to our understanding of normal skin wound healing as well as to the pathogenesis of wound disorders. Development of ncRNA-based biomarkers and treatments is an interesting and important avenue for future research on wound healing.

Keywords: wound healing, chronic wound, pathological scar, non-coding RNA, microRNA

\section{SCOPE AND SIGNIFICANCE}

IMPAIRED WOUND REPAIR, such as chronic wounds and pathological scars, is a major health and economic burden and efficient targeted treatment for these diseases is lacking, which is largely due to our limited understanding of their biological mechanisms. Non-coding RNAs
(ncRNAs) are recently identified gene regulators that are important for cellular physiology and pathology, which represent promising candidates for the development of new therapeutic and diagnostic approaches. In this review, we primarily focus on short ncRNAs, i.e., microRNAs (miRNAs), and long ncRNAs (lncRNAs), and

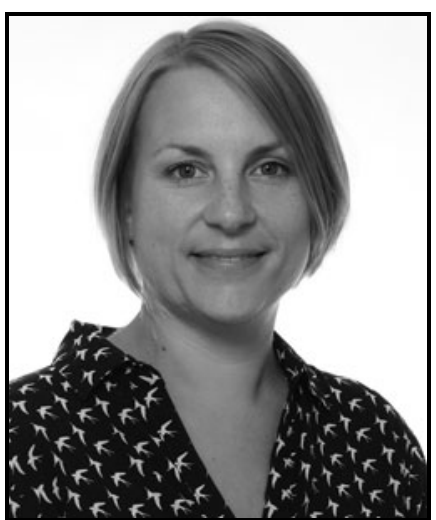

Eva K. Herter, PhD

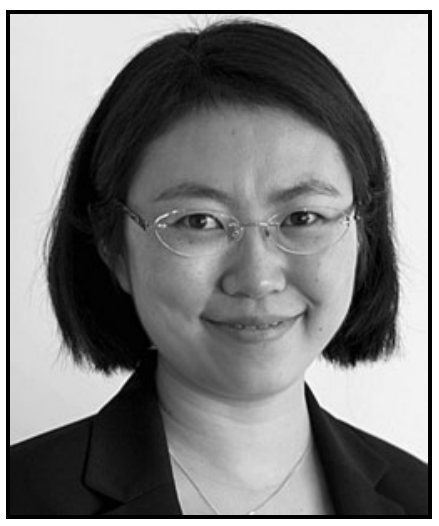

Ning Xu Landén, PhD

Submitted for publication October 1, 2016 Accepted in revised form November 26, 2016

${ }^{*}$ Correspondence: Molecular Dermatology Research Group, Department of Medicine, Center for Molecular Medicine (CMM), L8:02, Karolinska Institutet, Stockholm SE-17176, Sweden (e-mail: eva.herter@ki.se or ning.xu@ki.se). 
provide an overview about their roles in skin wound healing.

\section{TRANSLATIONAL RELEVANCE}

Due to their specific expression, both miRNAs and lncRNAs hold great promises to serve as a novel class of biomarkers for diagnosis, prognosis, and monitoring of treatment effects. Development of ncRNAbased biomarkers would be an important avenue for future research on wound healing. Moreover, the modulation of miRNAs may be a more effective strategy than traditional drugs targeting single proteins, since a single miRNA has the capacity to regulate an entire functional network. Therefore, investigating the role of miRNAs in wound repair may lead to a novel therapeutic approach for those wound complications that are difficult to treat to date.

\section{CLINICAL RELEVANCE}

Treatment of patients with complications in wound healing remains a major challenge. Understanding the molecular pathogenesis of chronic wounds and pathological scars will lead to development of more effective treatments, improving the life quality of patients and reducing the costs of wound care. An investigation of the role of ncRNAs represents an emerging concept, and it constitutes a promising area for pharmaceutical intervention. Moreover, ncRNAs are promising candidates for biomarkers to assess wounds to aid in timing of wound closure and to guide therapy.

\section{BACKGROUND}

\section{Skin wound healing}

Wound healing is an essential physiological process that is utilized to keep the integrity of the skin. It is a complex and dynamic process, requiring a well-orchestrated cooperation of different cell types. Wound healing is often characterized as four sequential but overlapping phases: hemostasis (0-several hours after injury), inflammation (13 days), proliferation (4-21 days), and remodeling (21 days- 1 year). ${ }^{1}$ Various mechanical and pathological factors, e.g., pressure, arterial or venous insufficiency, systemic inflammatory diseases, or diabetes mellitus, can impair the normal delicate healing response, resulting in chronic non-healing wounds, which present a major health and economic burden worldwide. ${ }^{2}$ For instance, in Europe and Scandinavia, the associated costs for treating chronic wounds account for 2-4\% of the total healthcare expenses. ${ }^{3}$ This burden is continuously growing, resulting from increasing healthcare costs, population aging, and escalating prevalence of diabetes. ${ }^{2}$ Chronic wounds cause pain, disability, depression, and social isolation, severely affecting the life quality of patients. ${ }^{4}$ Moreover, an increased risk for mortality has been shown in patients with chronic wounds. ${ }^{5,6}$ The increased age of patients and the complex nature of wound environments make chronic wounds difficult to treat, and a high rate of recurrence has been observed. ${ }^{2}$ Another burden of skin wound healing is excessive scarring, such as hypertrophic scars (HTS) and keloids, which can occur after burns, surgery, trauma, or spontaneously in predisposed patients, leading to profound functional and aesthetic consequences. ${ }^{2}$ To date, there is still a lack of efficient targeted treatment approaches for these wound complications, which is largely due to our limited understanding of the biological mechanisms underlying these diseases. ${ }^{2,7}$

\section{Non-coding RNAs}

For decades, the focus of research has been centered on protein-coding genes, even though they constitute less than $2 \%$ of the human genome. However, in 2012, the ENCODE project stated that around $80 \%$ of the genome is transcribed. ${ }^{8}$ Therefore, the majority of the transcriptional output of the human genome is constituted by the RNAs that lack protein-coding capacity (Fig. 1). ${ }^{9,10}$ Among the ncRNAs, only a few classes have been characterized for their functional roles. For instance, transfer RNAs (tRNAs) and ribosomal RNAs (rRNAs) are indispensable for translation of messenger RNAs (mRNAs) into proteins. ${ }^{11}$ Small nucleolar RNAs (snoRNAs) are responsible for the modifications of rRNAs and tRNAs. ${ }^{12}$ Small nuclear RNAs (snRNAs) play an important role in the process of RNA splicing. ${ }^{13}$ Besides these housekeeping ncRNAs, most of the other ncRNAs have been considered "side-products" of gene transcription and without any functional importance. This view was changed with the discovery of miRNAs in the $1990 \mathrm{~s} .{ }^{14}$ Intensive research in the past two decades has revealed that many ncRNAs actually function as important regulators of cellular physiology and pathology, which makes them promising therapeutic and diagnostic entities. In this review, we primarily focus on short ncRNAs, i.e., miRNAs, and lncRNAs (Table 1), and provide an overview about their roles in skin wound healing.

MicroRNAs. miRNAs are short ncRNAs with an average length of 22 nucleotides. Their primary precursors (pri-miRNAs) are mainly transcribed by RNA Polymerase II. ${ }^{15}$ The pri-miRNAs are cleaved by the nuclear RNase III Drosha to form a shorter RNA with a hairpin structure, i.e., pre-miRNAs, 


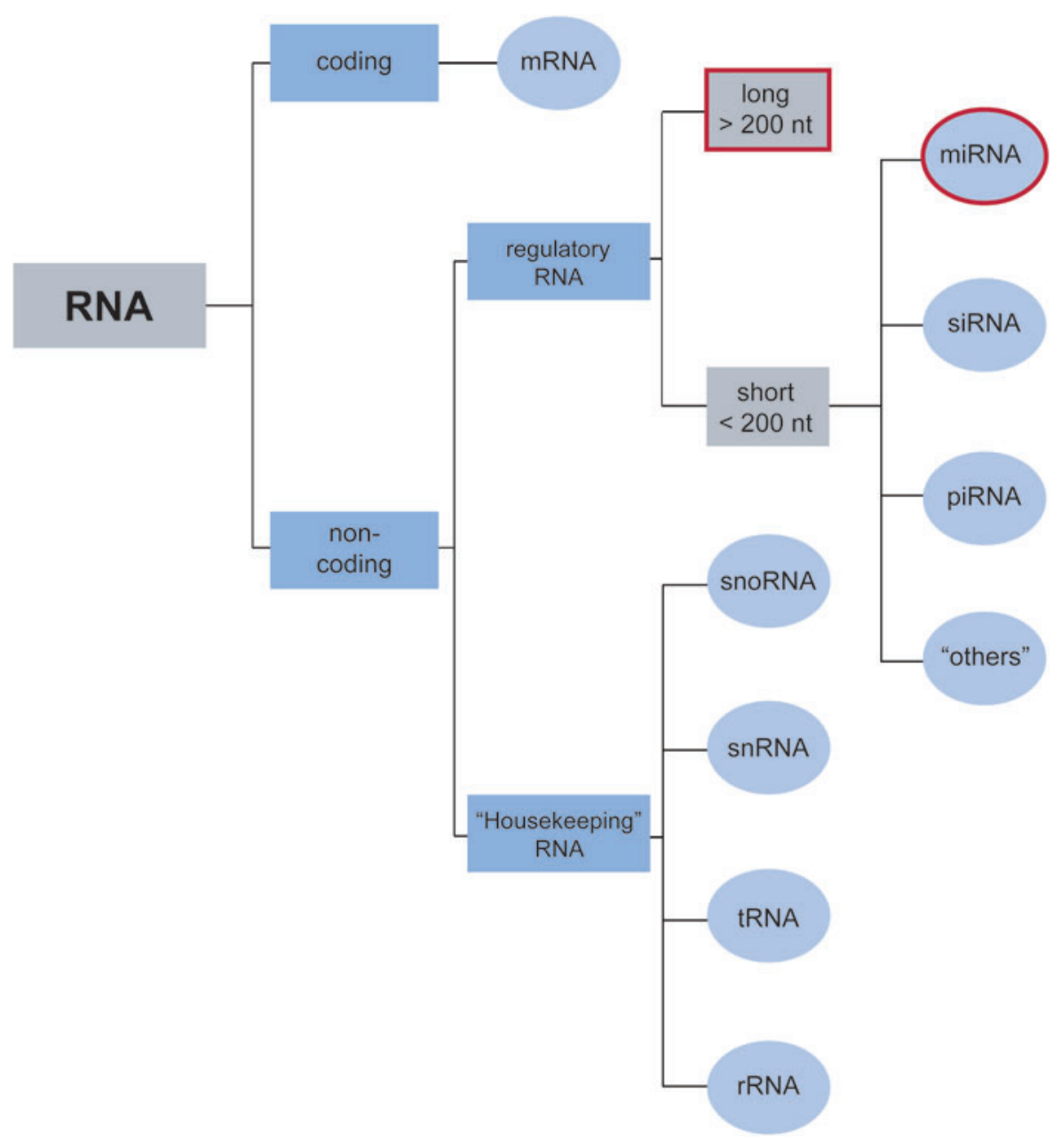

Figure 1. Classification of RNAs. mRNA, messenger RNA; miRNA, microRNA; piRNA, piwi-interacting RNA; rRNA, ribosomal RNA; siRNA, short-interfering RNA; snRNA, small nuclear RNA; snoRNA, small nucleolar RNA; tRNA, transfer RNA. To see this illustration in color, the reader is referred to the web version of this article at www.liebertpub.com/wound

and then transported into the cytoplasm. ${ }^{15}$ After subsequent cleavage by the cytoplasmic RNase III DICER, the mature miRNAs incorporate into the RNA-induced silencing complex and bind to the $3^{\prime}$ untranslated region (UTR) of the target mRNA, which results in translational repression or degradation of the target mRNA. ${ }^{15}$ It has been proposed that the majority of protein-coding genes in humans are regulated by miRNAs. ${ }^{16}$ Recent clinical trials have demonstrated that the modulation of

Table 1. Comparison of miRNAs and IncRNAs

\begin{tabular}{|c|c|c|}
\hline & microRNA & Long Non-Coding RNA \\
\hline Coding potential & \multicolumn{2}{|c|}{ Non-protein coding, regulatory functions } \\
\hline Functions & \multicolumn{2}{|c|}{ Important roles in both physiological and pathological conditions } \\
\hline Length & $\sim 22 \mathrm{nt}$ & $>200 \mathrm{nt}$ \\
\hline Conservation & Highly conserved between species & Poorly conserved between species \\
\hline Expression pattern & Not specific & Often highly tissue/cell type specific \\
\hline Number in human & 2,588 & $\sim 60,000$ \\
\hline Biogenesis & $\begin{array}{l}\text { Majority transcribed by RNA Pol II as primary transcripts (pri-miRNAs) } \\
\text { Drosha- and Dicer-dependent cleavage } \\
\text { Mostly intronic and intergenic }\end{array}$ & $\begin{array}{c}\text { Majority transcribed by RNA Pol II orientated sense, antisense, } \\
\text { bidirectional, intronic, or intergenic to protein coding genes }\end{array}$ \\
\hline Action modes & Post-transcriptional gene silencing & $\begin{array}{l}\text { Regulation of gene transcription } \\
\text { Post-transcriptional regulation } \\
\text { Epigenetic regulation } \\
\text { Regulation of chromatin structure } \\
\text { Other mechanisms of action }\end{array}$ \\
\hline
\end{tabular}


miRNA expression by the administration of specific miRNA mimics or inhibitors has beneficial effects on several diseases. ${ }^{17}$ Importantly, the modulation of miRNAs may be a more effective strategy than traditional drugs targeting single proteins, since a single miRNA may regulate multiple targets within a functional network. Here, we focus on the recent research progress on the roles of miRNAs in skin wound healing, the knowledge of which is a prerequisite for the development of an miRNAbased treatment to improve wound repair.

Long ncRNAs. lncRNAs are defined as the ncRNAs that are more than 200 nucleotides long and that represent a large and diverse class of ncRNA molecules. ${ }^{10}$ Although 60,000 lncRNAs have been discovered in humans, only a small portion has been characterized in detail. ${ }^{18}$ Some of them are transcribed as natural antisense transcripts to coding genes, located between genes or within introns. Some of them are derived from pseudogenes. ${ }^{19}$ According to their localization and direction of transcription in relation to protein coding genes, lncRNAs are categorized into different sub-groups, i.e., antisense, intergenic, overlapping, intronic, bidirectional, and processed ${ }^{20} \mathrm{In}$ general, compared with mRNAs, lncRNAs are less abundant in the cell and are expressed in a more tissue- and cell-type specific fashion. ${ }^{21}$ lncRNAs can inhibit or activate gene expression through a variety of mechanisms (Fig. 2). For instance, they can act in transcriptional regulation or in chromatin modification both in cis and in trans; they can serve as precursors for smaller regulatory RNAs, e.g., miRNAs or piRNAs; they can bind to complementary RNA and affect RNA processing, turnover, or localization; and they can interact with proteins, forming riboprotein complexes and affecting protein function and localization (Fig. 2). ${ }^{22}$ The important regulatory roles of lncRNAs have been recently revealed in the skin, such as in epidermal development, keratinocyte differentiation, and melanocyte functions. ${ }^{23}$ However, their function in skin wound healing remains largely unexplored. A comparison between lncRNAs and miRNAs can be found in Table 1 .

\section{DISCUSSION OF FINDINGS AND RELEVANT LITERATURE miRNAs in skin wound healing}

Extensive studies over the past two decades have provided important insights into the function of miRNAs in a wide range of physiological and pathological conditions. The essential role of
A

Regulation of transcription

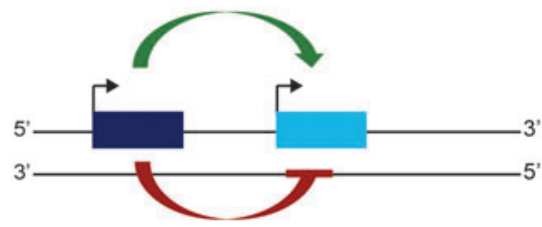

B

Interaction with proteins

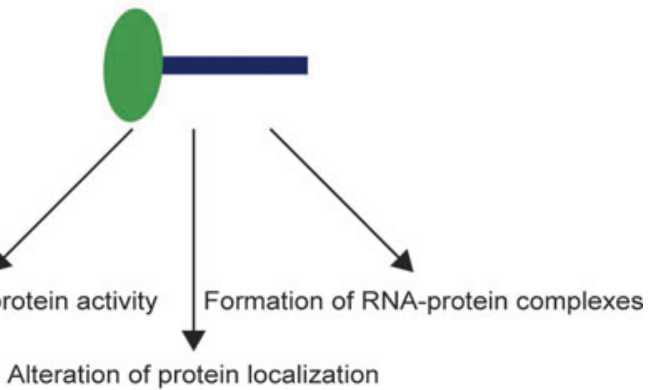

C Hybridization of sense and antisense RNA

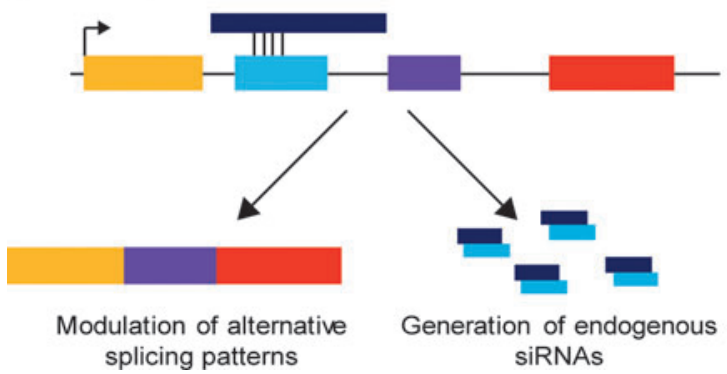

D Small RNA precursor

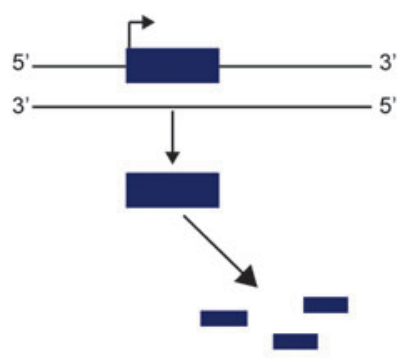

Figure 2. Overview of some action modes of IncRNAs. (A) IncRNAs can regulate downstream gene transcription by inhibiting RNA polymerase II recruitment or by inducing chromatin remodeling and histone modifications. (B) IncRNAs can bind to protein partners to modulate protein activity, alter protein localization in the cell, or serve as structural components for larger RNA-protein complexes. (C) By hybridizing to the complementary transcript, antisense IncRNA can modulate alternative splicing patterns or allow Dicer to generate endogenous siRNAs. (D) IncRNAs can be further processed to generate small RNAs such as miRNAs or piRNAs. To see this illustration in color, the reader is referred to the web version of this article at www.liebertpub.com/wound 
miRNAs in skin wound healing has been recently revealed. Ghatak et al. showed that the expression of Dicer, an enzyme essential for miRNA biogenesis, was increased during wound healing; depletion of Dicer in keratinocytes in mice before wounding impaired wound closure. ${ }^{24}$ In this review, we summarized the function of individual miRNAs in the various phases of skin wound healing (Table 2 ).

Hemostasis and inflammation. When skin gets injured, clotting factors are released immediately and activate the extrinsic clotting cascade. ${ }^{1}$ The thrombocytes are activated and aggregate, which leads to formation of a blood clot containing fibrin, vitronectin, fibronectin, and thrombospondin. ${ }^{25}$ This provisional wound matrix provides a scaffold for the migration of fibroblasts, keratinocytes, and leukocytes. ${ }^{1}$ The activated platelets release large amounts of cytokines and growth factors that are critical for wound repair, such as epidermal growth factor (EGF), transforming growth factor (TGF), and the platelet-derived growth factor (PDGF). Degranulation of platelets also activates the complement cascade. ${ }^{26}$ In response to chemokines, complements, and invading bacteria, neutrophils are recruited from the circulation to the wound site, which perform phagocytosis and are important for cleaning the pathogens and cell debris from the wound. ${ }^{27}$ Approximately 3 days after injury, a large amount of monocytes enter the wound site, are activated by local signals, and differentiate into macrophages with various functional phenotypes. $^{28}$ On exposure to pro-inflammatory cytokines, interferons (IFNs), microbes, or stressed cells, macrophages with a pro-inflammatory phenotype (M1 subset) predominate the early phase of wound repair; perform phagocytosis of microbes; scavenge cellular debris; and produce proinflammatory mediators. ${ }^{29}$ Later during the healing process, interleukin (IL)-4, IL-10, glucocorticoids, prostaglandins, and modulators of glucose and lipid metabolism induce macrophages to switch to a reparative phenotype (M2 subset), which secretes anti-inflammatory mediators and growth factors, promoting fibroblast proliferation, angiogenesis, and extracellular matrix (ECM) synthesis. ${ }^{30}$ Moreover, macrophages play a central role in removing neutrophils from the wounds by phagocytosis, which, in turn, induces the M1-M2 phenotype switch of macrophages. ${ }^{31}$ The transition from M1 to

Table 2. MicroRNAs in normal skin wound healing

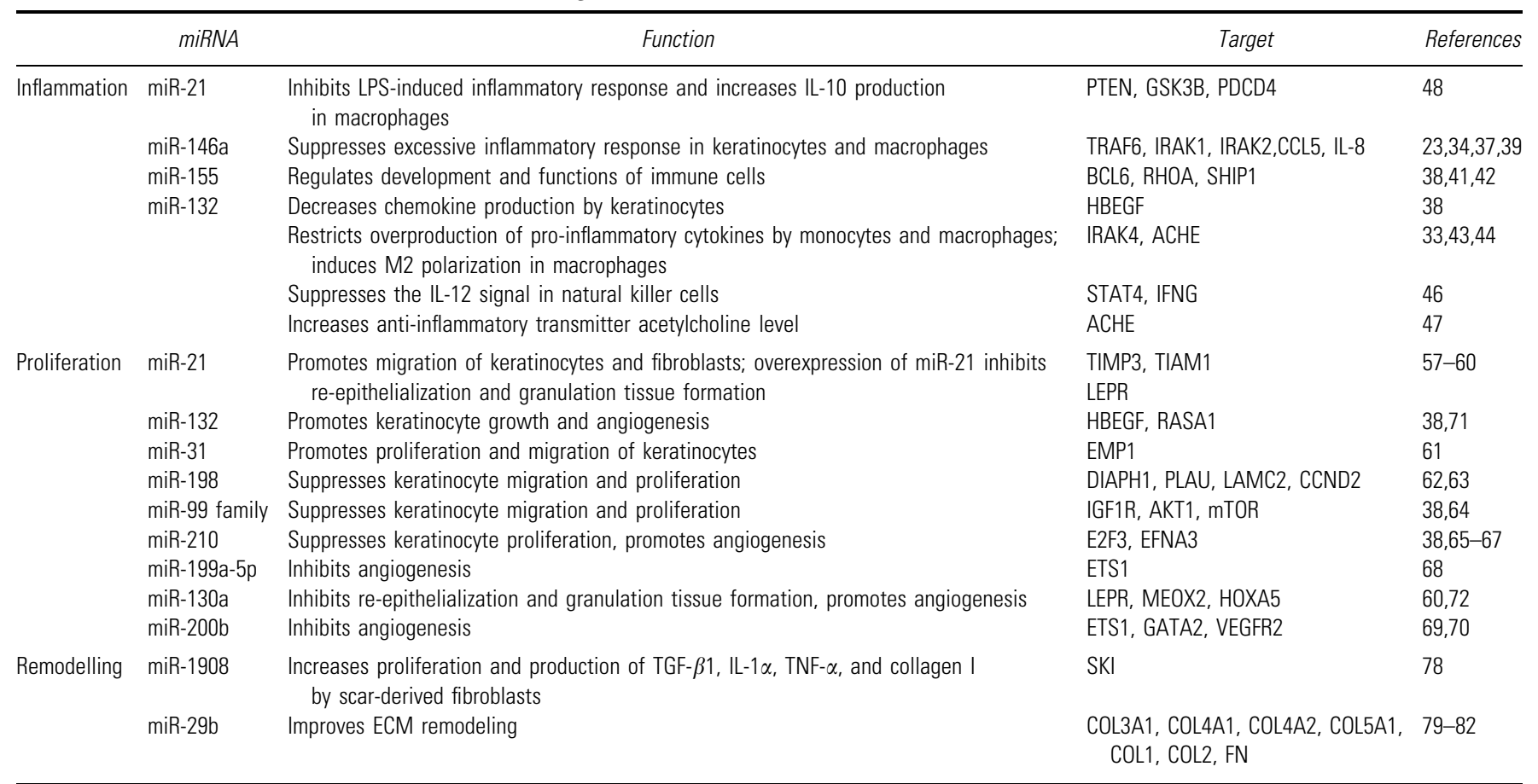

ACHE, acetylcholinesterase; AKT1, V-Akt murine thymoma viral oncogene homolog 1; BCL6, B cell CLL/lymphoma 6; CCL5, chemokine (C-C motif) ligand 5; CCND2, cyclin D2; COL, collagen; DIAPH1, diaphanous-related formin 1; EMP1, epithelial membrane protein 1; E2F3, E2F transcription factor 3; ETS1, erythroblastosis virus 26 oncogene homolog 1; ECM, extracellular matrix; EFNA3, ephrin-A3; FN, fibronectin; GSK3B, glycogen synthase kinase 3B; GATA2, globin transcription factor binding protein 2; HBEGF, heparin-binding EGF-like growth factor; IL, interleukin; IRAK, interleukin 1 receptor-associated kinases; IFNG, interferon gamma; IGF1R, insulin-like growth factor 1 receptor; LPS, lipopolysaccharide; LEPR, leptin receptor; LAMC2, laminin subunit gamma 2; mTOR, mechanistic target of rapamycin; PTEN, phosphatase and tensin homolog; PDCD4, programmed cell death protein 4; PLAU, plasminogen activator urokinase; RHOA, Ras homolog family member A; RASA1, Ras P21 protein activator 1; SHIP1, inositol polyphosphate-5-phosphatase D; STAT4, signal transducer and activator of transcription 4; TRAF6, TNF receptor-associated factor 6; TIMP3, TIMP Metallopeptidase Inhibitor 3; TIAM1, T cell lymphoma invasion and metastasis 1; VEGFR2, vascular endothelial growth factor receptor 2. 
M2 macrophages is an essential step in wound healing, and impairment of the transition has been implicated in the pathogenesis of chronic wounds. ${ }^{32}$ Interestingly, miRNAs have been involved in regulating the polarization of macrophages. For instance, miR-9, miR-127, miR-155, and miR-125b promote M1 polarization; whereas miR-124, miR223, miR-34a, let-7c, miR-132, miR-146a, and miR$125 \mathrm{a}-5 \mathrm{p}$ induce M2 polarization. $^{33}$

At the early stage of wound healing, several miRNAs have been revealed to play critical roles. miR-146a, miR-155, miR-125b, and miR-132 were the first miRNAs linked to inflammatory response, which expression was induced in a monocytic cell line treated with lipopolysaccharide (LPS), a ligand to Toll-like receptor 4 (TLR4). ${ }^{34,35}$ The increased expression of miR-146a was also observed in epidermal keratinocytes stimulated with the ligands to TLR2, TLR3, or TLR5. ${ }^{36}$ miR-146a was found to negatively regulate inflammatory response in monocytes, macrophages, and keratinocytes by targeting the IL-1 receptor-associated kinases 1 (IRAK1), IRAK2, and tumor necrosis factor receptor-associated factor 6 (TRAF6), several key factors within the NF- $\kappa \mathrm{B}$ signaling pathway. ${ }^{23,34,37}$ These evidences suggest that miR-146a may function as a brake of inflammatory response and facilitate inflammation resolution. We have found that at the inflammatory phase of human skin wound healing, miR-146a was downregulated compared with the intact skin, reflecting the need of an efficient immune response at this stage of wound repair. ${ }^{38}$ Interestingly, decreased miR-146a expression was observed in the wounds of a diabetic mouse model, which correlates with the enhanced expression of its targets, i.e., IRAK1, TRAF6, and increased $\mathrm{NF}-\kappa \mathrm{B}$ signaling in the same model. ${ }^{39}$

miR-155 is a multifunctional miRNA that is important for the development and functioning of immune cells. ${ }^{40}$ It has been shown that miR-155 is upregulated at the inflammatory phase in skin wounds of both humans and mice. ${ }^{38,41}$ Treatment of the wounds in mice with miR-155-specific inhibitors reduced the recruitment of inflammatory cells into the wound site and improved the architecture of the regenerated tissues. ${ }^{42}$ In line with this, miR-155 mutant mice exhibited quicker wound closure accompanied by an increased type-1 collagen deposition, in comparison to wild-type mice. ${ }^{41}$

The anti-inflammatory role of miR-132 has been revealed in several cell types that are critical for skin wound healing. For example, in monocytes and macrophages, miR-132 is induced by TLR ligands and restricts the overproduction of proinflammatory cytokines. ${ }^{43,44}$ Moreover, miR-132 also induces M2 polarization in macrophages that are involved in immunosuppression and tissue repair. ${ }^{33}$ In neutrophils, the level of miR-132 is upregulated after extravasation and migration into the skin, indicating a potential functional role. ${ }^{45} \mathrm{In}$ natural killer cells, IL-12 treatment upregulates the expression of miR-132, which, in turn, suppresses the IL-12 signal, such as by decreasing the expression of the signal transducer and activator of transcription 4 (STAT4) and IFN $\gamma^{46}$ In addition, Shaked et al. found that inflammation induced the expression of miR-132 in leukocytes, which increased the level of anti-inflammatory transmitter acetylcholine by targeting acetylcholinesterase. ${ }^{47}$ Our recent study showed that miR-132 decreased the production of chemokines and the capability of keratinocytes to attract leukocytes by targeting heparin-binding EGF-like growth factor. ${ }^{38}$ In line with the anti-inflammatory functions of miR-132, we found that its expression was upregulated during the transition from the inflammatory to the proliferative phases of skin wound healing. ${ }^{38}$

miR-21 has been shown to be important for resolving inflammation. ${ }^{48,49}$ Its expression is induced in macrophages by resolving D1, an endogenous lipid mediator produced during inflammation resolution. ${ }^{49}$ Also, the level of miR-21 is increased in macrophages after engulfment of apoptotic neutrophils, which is a key process to shift inflammation toward tissue repair. ${ }^{48}$ In macrophages, miR-21 inhibits the LPS-induced inflammatory response by silencing its targets, phosphatase and tensin homolog (PTEN) and glycogen synthase kinase (GSK) $3 \beta$. Moreover, by targeting programmed cell death protein 4 (PDCD4), miR-21 promotes the activity of c-Jun-AP1 , which leads to increased production of IL-10, an anti-inflammatory cytokine, by macrophages. ${ }^{48}$

Several miRNAs have been involved in regulating polarization and the inflammatory response of macrophages, indicating that they may play a role in wound healing. For instance, miR-125b has been shown to be downregulated in LPS-treated macrophages. ${ }^{35,50,51}$ Overexpression of miR-125b enhances responses of macrophages to the M1 inducer IFN $\gamma$, thus potentiating the role of macrophages in inducing immune responses. ${ }^{52}$ miR-223 induces M2 polarization in macrophages. ${ }^{53}$ Its overexpression in macrophages inhibits LPS-stimulated release of IL- 6 and IL- $1 \beta$ by targeting STAT3 ${ }^{53}$ Interestingly, miR-223 expression has been found to be upregulated in human wounds at the inflammatory phase compared with the intact skin. ${ }^{38}$

Proliferation. The proliferative phase typically occurs 1-3 weeks after injury and is dedicated to 
covering the wound surface (re-epithelialization), restoring the vascular network (angiogenesis/ neovascularization), and forming granulation tissue. ${ }^{25}$ Re-epithelialization starts with local keratinocyte migration across the wound bed, which happens in a few hours to 1 day after injury. ${ }^{54,55}$ Approximately 2-3 days later, basal layer keratinocytes and epithelial stem cells from nearby hair follicles and sweat glands start to proliferate to generate more keratinocytes for wound repair. Reepithelialization is stimulated by various growth factors and cytokines, such as EGF, keratinocyte growth factor, nerve growth factor, and insulin growth factor-1 (IGF-1). ${ }^{56}$ To supply the new forming tissue with nutrients, it is essential to restore the vascular network. Angiogenesis is initiated by different growth factors, e.g., PDGF, vascular endothelial growth factor (VEGF), fibroblast growth factor 2 (FGF2), and the serine protease thrombin. ${ }^{1}$ During the proliferative phase, the provisional wound matrix formed earlier is replaced by the granulation tissue, which contains a high density of fibroblasts, granulocytes, macrophages, capillaries, and collagen bundles, forming a scaffold for cell adhesion, migration, and growth in the wound. ${ }^{1}$

miR-21 has been found to play an important role not only in the inflammatory phase but also in the proliferative phase. On wounding, the expression of miR-21 was upregulated in wound-edge keratinocytes and dermal mesenchymal cells. ${ }^{57,58}$ miR-21 has been shown to promote migration of both keratinocytes and fibroblasts. ${ }^{58,59}$ Inhibition of miR-21 in the wound delays re-epithelialization and impairs wound contraction and collagen deposition. ${ }^{57,58}$ Conversely, Pastar et al. showed that local overexpression of miR-21 delayed re-epithelialization in an acute human skin ex vivo wound model, as well as inhibited re-epithelialization and granulation tissue formation in a rat wound model. ${ }^{60}$ These seemingly contradictory results indicate the importance of tight control of miR-21 level during wound healing.

miR-132 is another miRNA that is critical for both inflammatory and proliferative phases. We have recently found that miR-132 promoted keratinocyte growth by increasing the activity of the STAT3 and the mitogen-activated protein kinase (MAPK) signaling pathways. ${ }^{38}$ Moreover, using the mouse in vivo and human ex vivo wound model, we showed that blockage of miR-132 led to severe inflammation, decreased keratinocyte growth, and delayed wound closure. ${ }^{38}$

miR-31 was found to be highly upregulated in human wound-edge keratinocytes in the proliferative phase compared with the inflammatory phase or the intact skin. ${ }^{61}$ In line with this, miR-31 promotes proliferation and migration of keratinocytes by targeting the epithelial membrane protein 1 (EMP-1), contributing to wound re-epithelialization. ${ }^{61}$

miRNA-198 is a miRNA, inhibiting keratinocyte migration and proliferation. ${ }^{62,63}$ Interestingly, miR-198 is derived from the $3^{\prime}$-UTR of follistatinlike 1 (FSTL1) mRNA, which codes a protein promoting keratinocyte migration. ${ }^{62}$ During wound healing, TGF- $\beta$ decreases the expression of $\mathrm{KH}$ type splicing regulatory protein (KSRP), which is essential for miR-198 processing. Consequently, the expression of miR-198 is turned off, whereas the expression of FSTL1 is switched on, allowing keratinocyte migration. ${ }^{62}$ Impairment of this switch, as shown in chronic diabetic ulcers, results in deficiency in keratinocyte migration, reepithelialization, and wound closure. ${ }^{62}$

Several members of the miR-99 family, including miR-99a, miR-99b, and miR-100, have been found to be downregulated at the inflammatory phase in both human and mouse wound models. $^{38,64}$ Downregulation of the miR-99 family members results in increased expression of their targets, i.e., IGF-1 receptor (IGF1R), mechanistic target of rapamycin, and V-Akt murine thymoma viral oncogene homolog 1 (AKT1), which, in turn, increase keratinocyte proliferation and migration, facilitating wound closure. ${ }^{64}$

A high level of hypoxia in ischemic chronic wounds induces the expression of miR-210, which inhibits keratinocyte proliferation and wound reepithelialization by targeting cell-cycle regulatory protein E2F transcription factor 3 (E2F3). ${ }^{65}$ Moreover, miR-210 has been shown to repress mitochondrial metabolism and decrease oxygen cost of survival. ${ }^{66}$ In endothelial cells, hypoxia-induced miR-210 promotes angiogenesis by targeting Ephrin-A3 (EFNA3). ${ }^{66}$ In normal human skin wounds, miR-210 has been found to be downregulated at the inflammatory phase compared with the intact skin. ${ }^{38}$ Recently, Ghatak et al. delivered the miR-210 inhibitor encapsulated in lipid nanoparticles into murine ischemic skin wounds, which effectively accelerated wound closure, demonstrating miR-210 as a promising therapeutic target to improve wound healing. ${ }^{67}$

Several miRNAs have been identified as important regulators of angiogenesis during skin wound healing. For instance, miR-199a-5p is downregulated in dermis and endothelial tissue during skin wound healing. ${ }^{68}$ Chan et al. found that miR-199a-5p negatively regulated angiogenic responses of human dermal microvascular endothelial cells by targeting a crucial angiogenesis-related transcription factor, 
i.e., avian erythroblastosis virus 26 oncogene homolog 1 (ETS1), and its downstream mediator, matrix metalloproteinase $1 .^{68}$ Accordingly, mice with homozygous deletions in the ETS1 gene exhibit impaired angiogenesis, insufficient granulation tissue formation, and compromised wound closure. ${ }^{68}$ Similarly, miR-200b, which is downregulated by hypoxia in endothelial cells, also suppresses angiogenesis by targeting ETS1, globin transcription factor binding protein 2 (GATA2), and VEGF receptor 2 (VEGFR2) expression. ${ }^{69,70}$ On the other hand, both VEGFA and FGF2 enhance the expression of miR-130a and miR-132 in endothelial cells. ${ }^{71,72}$ miR-130a promotes angiogenesis by targeting mesenchyme homeobox2 (MEOX2) and homeobox A5 (HOXA5). ${ }^{72}$ miR-132 increases endothelial cell proliferation and vascularization by targeting RAS p21 protein activator 1 (RASA1). ${ }^{71}$

Remodeling. The final stage of wound healing is the remodeling phase. Due to stimulation of mechanical tension and cytokines, such as TGF- $\beta$, fibroblasts differentiate into myofibroblasts, which attach to collagen and induce wound contraction. ${ }^{73}$ Granulation tissue stops growing, whereas cells undergo apoptosis. ${ }^{74}$ In the ECM, type I collagen, which has a higher tensile strength, replaces the quickly produced type III collagen. ${ }^{74}$ The wound-healing cascade ends with scar formation, and the healed skin can achieve maximally $\sim 80 \%$ of the original tensile strength. ${ }^{75}$ Interestingly, it is known that human fetuses have the ability to heal without scarring until the 24th week of gestation, although the underlying mechanism remains unclear. ${ }^{76}$

miR-1908 has recently been demonstrated to target SKI, a protein that reduces scar formation in rats by decreasing collagen production and relieving inflammation. ${ }^{77}$ The expression levels of miR1908 and SKI are inversely correlated in the intact and wounded skin as well as in the scar tissues of humans. ${ }^{78}$ miR-1908 increases cell proliferation and production of TGF- $\beta 1$, IL- $1 \alpha$, tumor necrosis factor (TNF- $\alpha$ ), and type I collagen by fibroblasts derived from human scars. ${ }^{78}$ An injection of miR1908 inhibitors into the burn-wounded scars of rats reduced the area, volume, and fibrosis of scars. ${ }^{78}$

miR-29b has been associated with TGF- $\beta 1$ directed fibrogenesis, and it targets multiple ECM genes, such as COL3A1, COL4A1, COL4A2, and COL5A1. ${ }^{79-81}$ Importantly, local delivery of miR$29 \mathrm{~b}$ using a collagen scaffold has been shown to significantly reduce wound contraction and increase collagen type III/I ratios, improving ECM remodeling in a rat wound model. ${ }^{82}$

\section{miRNAs in wound complications}

As discussed earlier, miRNAs are indispensable for all the steps of skin wound healing. It is not surprising that accumulating evidences demonstrate that aberrant expression of miRNAs contributes to the pathogenesis of major wound complications, such as pathological scars and chronic non-healing wounds (Table 3 ). The findings about the miRNA-mediated regulation, from a new angle, add to our understanding about molecular mechanisms of these diseases, which may also lead to the development of novel therapeutic approaches to improve wound healing.

Pathological scars. Excessive scarring leads to profound functional and aesthetic consequences and lacks effective treatment to date. ${ }^{2}$ It is classified into HTS and keloids, which are different in clinical appearance, histology, and epidemiology. ${ }^{83}$ In general, both scar types are characterized by an increased number of myofibroblasts and excessive ECM deposition. ${ }^{83}$ TGF- $\beta$ signaling has been shown to play a central role in the pathogenesis of excessive scarring. ${ }^{83}$

Recent findings about miRNA-mediated regulation in excessive scarring significantly enhance our understanding about this disease (Table 3). For instance, miR-145 has been found to be upregulated in HTS compared with healthy skin, the expression of which is induced by TGF- $\beta 1$ in fibroblasts. ${ }^{84}$ miR-145 increases the level of $\alpha$-smooth muscle actin ( $\alpha$-SMA), an important contributor to contractile force generation in myofibroblasts, by directly targeting a known inhibitor of $\alpha$-SMA, Kruppel-like factor 4 (KLF4). ${ }^{84}$ Treatment of myofibroblasts with miR-145 inhibitors strongly reduced the expression of collagen I and TGF- $\beta 1$, as well as decreased contractile force generation and migration. ${ }^{84}$ On the contrary, miR-143-3p expression has been found to be decreased in fibroblasts derived from human HTS. ${ }^{85} \mathrm{Mu}$ et al. showed that miR-143-3p inhibited proliferation but promoted apoptosis of HTS fibroblasts, and it suppressed expression of collagen I, collagen III, and $\alpha$-SMA, thus inhibiting HTS formation. ${ }^{85}$ Decorin (DCN) is a proteoglycan that reduces fibrosis and induces regeneration in many tissues; however, it is significantly downregulated in HTS. ${ }^{86} \mathrm{Kwan}$ et al. found that DCN was targeted by miR-181b, which is an miRNA that is increased in HTS. ${ }^{86}$ Inhibition of miR-181b in HTS fibroblasts reversed TGF- $\beta 1$ induced DCN downregulation and myofibroblast differentiation, suggesting its therapeutic potential for HTS. ${ }^{86}$ In 2012, Kashiyama et al. identified a unique miRNA signature in keloid-derived 
Table 3. MicroRNAs in wound complications

\begin{tabular}{|c|c|c|c|c|}
\hline & miRNA & Function & Target & References \\
\hline \multirow{4}{*}{ Hypertrophic scar } & miR-143-3p & Inhibits HTS formation by regulating proliferation and apoptosis of fibroblasts & CTGF & 85 \\
\hline & miR-21 & Promotes fibroblast proliferation & SMAD7, PTEN & $90,94,95$ \\
\hline & miR-200b & Inhibits proliferation and promotes apoptosis of HTS fibroblasts & ZEB1 & 91,94 \\
\hline & $\begin{array}{l}\text { miR-10a } \\
\text { miR-181c }\end{array}$ & Regulates collagen I generation & $\begin{array}{l}\text { PAl1 } \\
\text { PLAU }\end{array}$ & 89 \\
\hline \multirow{3}{*}{ Keloid } & miR-29a & Decreases collagen expression in fibroblasts & COL3A1 & 88 \\
\hline & miR-21 & Increases fibroblast proliferation & PTEN & 92 \\
\hline & miR-199a-5p & Inhibits fibroblast proliferation & DDR1, PODXL & 93 \\
\hline \multirow[t]{4}{*}{ Chronic wound } & miR-26a & Inhibits angiogenesis, granulation tissue formation and impairs wound closure & SMAD1 & 101 \\
\hline & miR-155 & Suppresses proliferation and migration of endothelial cells & SIRT1 & 102 \\
\hline & miR-200b & Inhibits angiogenesis & GATA2, VEGFR2 & 70 \\
\hline & $\begin{array}{l}\text { miR-146a } \\
\text { miR-106b }\end{array}$ & $\begin{array}{l}\text { Is induced in wounds infected with biofilms and leads to impaired } \\
\text { epidermal barrier function }\end{array}$ & Z01, ZO2 & 109 \\
\hline
\end{tabular}

CTGF, connective tissue growth factor; DCN, decorin; DDR1, discodin domain receptor tyrosine kinase-1; HTS, hypertrophic scar; HIF1A, hypoxia-inducible factor 1 alpha; KLF4, Kruppel-like factor 4; PAl1, plasminogen activator inhibitor-1; PODXL, podocalyxin-like; SMAD, SMAD family member; SIRT1, sirtuin-1; SHC1, Src homology 2 domain containing transforming protein 1; SEMA6A, semaphoring 6A; TSP, thrombospondin; VEGFA, vascular endothelial growth factor A; ZEB1, zinc finger E-box binding homeobox 1; ZO, zona occludens.

fibroblasts compared with normal fibroblasts. ${ }^{87}$ Among the differentially expressed miRNAs, they focused on miR-196a, which was strongly downregulated in keloid fibroblasts, and demonstrated that it targeted and downregulated the expression of type I and type III collagens in keloid fibroblasts. ${ }^{87}$ Recently, miR-29a, another miRNA with decreased expression in keloid fibroblasts, was also shown to negatively regulate type I/III collagen expression. ${ }^{88}$ Further miRNAs involved in pathological scar formation include miR-21, which promotes fibroblast proliferation in HTS formation and in keloids; miR200b and miR-199a-5p, which inhibit fibroblast proliferation; and miR-10a and -181c, which regulate collagen I generation (Table 3). ${ }^{89-95}$

Chronic wounds. Chronic non-healing wounds are a major and rising health and economic burden worldwide. It is known that chronic wounds are trapped in a persistent inflammatory state and fail to progress through the normal wound-healing process. $^{32}$ In chronic wounds, a large amount of inflammatory cells are present at the wound site, which produce proteolytic enzymes, cytokines, and reactive oxygen species, destroying growth factors and ECM. ${ }^{32}$ Keratinocytes are hyperproliferative, but they lack migration and differentiation. ${ }^{96}$ Fibroblasts exhibit decreased growth and motility as well as impaired ECM deposition. ${ }^{96}$ Angiogenesis is also reduced in chronic ulcers. ${ }^{97}$
Accumulating evidences have demonstrated that miRNAs play a major role in the pathogenesis of chronic wounds (Table 3). In this field, a large part of studies focuses on the chronic diabetic wound, since it is one of the most difficult wounds to heal and to treat, leading to high mortality and amputation rate. ${ }^{98,99} \mathrm{~A}$ unique miRNA signature has been identified in the cutaneous wounds of a rat diabetic model compared with that in normal rats. ${ }^{100}$ Bioinformatic analysis suggests that these differentially expressed miRNAs may regulate the signaling pathways that are important for wound healing, e.g., MAPK, TGF- $\beta$, and Wnt signals. ${ }^{100}$ Several miRNAs have been demonstrated to be responsible for the abnormal cellular behavior in chronic wounds. For instance, miR-26a, which is upregulated in the wounds of a mouse diabetic model compared with normal mice, directly targets SMAD1 and increases expression of the cell cycle inhibitor p27. ${ }^{101}$ Inhibition of miR-26a induced angiogenesis, increased granulation tissue formation, and advanced wound closure. ${ }^{101} \mathrm{miR}-155$ was shown to suppress proliferation and migration of human endothelial cells by targeting Sirtuin-1 (Sirt-1). ${ }^{102}$ In line with this, the treatment of wounds in diabetic mice with bone marrow mesenchymal stem cells inhibited miR-155 expression and accelerated wound healing. ${ }^{102}$ As aforementioned, injury decreases miR-200b expression, which switches on angiogenesis. ${ }^{69,70}$ In diabetic 
mice, excessive TNF- $\alpha$ induces the expression of miR200b, which inhibits angiogenesis by targeting GATA2 and VEGFR2. ${ }^{70}$ In addition, miR-15b and miR-27b have been shown to play a role in angiogenesis in diabetic wounds. Increased expression of miR-15b leads to impaired angiogenesis, whereas miR-27b rescues the function of impaired bone marrow-derived angiogenic cells and accelerates wound healing. ${ }^{103,104}$ Of note, the animal models of diabetes used in these studies only exhibit a delayed healing response, but they do not entirely mimic the chronic wound situation. Recently, Dhall et al. successfully induced non-healing chronic wounds in mice under diabetic condition by inhibiting two key antioxidant enzymes, catalase and glutathione peroxidase. ${ }^{105}$ This model would be helpful in understanding the pathophysiology and in developing new diagnostic and therapeutic approaches for human chronic wounds.

Recently, miRNAs have been shown to be also present in the circulation in a stable form, functioning as messengers mediating cell communication. ${ }^{106}$ Dangwal et al. compared the plasma miRNA profile in type 2 diabetic patients with and without chronic wounds and identified 41 miRNA to be differentially expressed. Furthermore, they showed that proinflammatory stress increased endothelial- or platelet-derived secretion of miR-191, which was taken up by dermal endothelial cells or fibroblasts. By targeting zonula occludens-1 (ZO-1), miR-191 suppresses angiogenesis and fibroblast migration, and it, therefore, delays skin repair. ${ }^{107}$

Biofilms, which are communities of aggregated bacteria embedded in a self-secreted extracellular polysaccharide matrix, are often present in chronic wounds. Biofilms protect bacteria from host defenses and antibiotic treatment, impairing wound repair. ${ }^{108}$ Roy et al. found miR-146a and miR-106b to be induced on wound infection with biofilms in a porcine burn wound model. Increased expression of these miRNAs leads to compromised tight junction function by targeting ZO-1 and ZO-2 in keratinocytes, and therefore to impaired epidermal barrier function. ${ }^{109}$

\section{Other types of ncRNAs in the skin}

The knowledge about miRNAs involved in wound healing is constantly growing, whereas the expression and function of lncRNAs in this process remains largely unexplored. Intensive studies in recent years have revealed that many lncRNAs play important roles in various cell/tissue types under both physiological and pathological conditions. ${ }^{110}$ Notably, an increasing number of lncRNAs have been linked to the biological pro- cesses in the skin, e.g., tissue differentiationinducing ncRNA (TINCR) and anti-differentiation ncRNA (ANCR) (Fig. 3). ${ }^{111,112}$ TINCR is a $3.7 \mathrm{~kb}$ lncRNA that is mainly present in the cytoplasm of differentiated keratinocytes. ${ }^{111}$ It associates with mRNAs that are important for differentiation through a 25-nucleotide motif, while binding to the Staufen1 (STAU1) protein, which leads to increased stability of these differentiation-related mRNAs by STAU1. ${ }^{111}$ Therefore, TINCR is indispensable for keratinocyte differentiation. ${ }^{111}$ In contrast, ANCR has been shown to be strongly downregulated during differentiation of keratinocytes, adipocytes, and osteoblasts. ${ }^{112}$ It is important to repress the epidermal differentiation program and to maintain the undifferentiated state in the epidermal progenitor compartment. ${ }^{112}$ Interestingly, a recent study reveals that both ANCR and TINCR act upstream of MAF and MAFB, which are transcription factors that are both sufficient and essential for epidermal differentiation (Fig. 3). ${ }^{113}$ Since keratinocyte differentiation is a key step of skin wound healing, which is impaired in chronic wounds, ${ }^{96}$ we propose that these lncRNAs may also play a regulatory role during skin wound repair, which warrants future investigation.

It has been known that keratinocytes require TLR3 to respond to RNA from damaged cells due to skin injury or prolonged exposure of ultraviolet (UV) B-radiation, with the release of inflammatory cytokines, e.g., TNF- $\alpha$ and IL-6, and increased expression of the genes involved in repair and maintenance of the epidermal permeability barrier. ${ }^{114-116}$ Bernard et al. found that UV-B induced structure alterations of an ncRNA, i.e., snRNA U1, which activated TLR3 in keratinocytes and contributed to inflammatory response and wound repair ${ }^{114}$ (Fig. 3). It is not clear whether this TLR3 activation during wound repair is unique to snRNAs, or may involve other ncRNAs, which is an interesting question that is needed to be answered by further research.

The expression and function of lncRNAs have also been characterized in various skin diseases, such as psoriasis, which is a chronic inflammatory skin disease sharing many common properties with wound healing $^{117}$ (Fig. 3). Using differential display, an lncRNA, psoriasis susceptibility-related RNA gene induced by stress (PRINS), was found to be increased in the epidermis of psoriasis patients. ${ }^{118}$ Later studies showed that PRINS contributes to cellular stress response and apoptosis in keratinocytes. ${ }^{119}$ With the advancement of gene profiling technologies, more detailed pictures of lncRNA expression in 


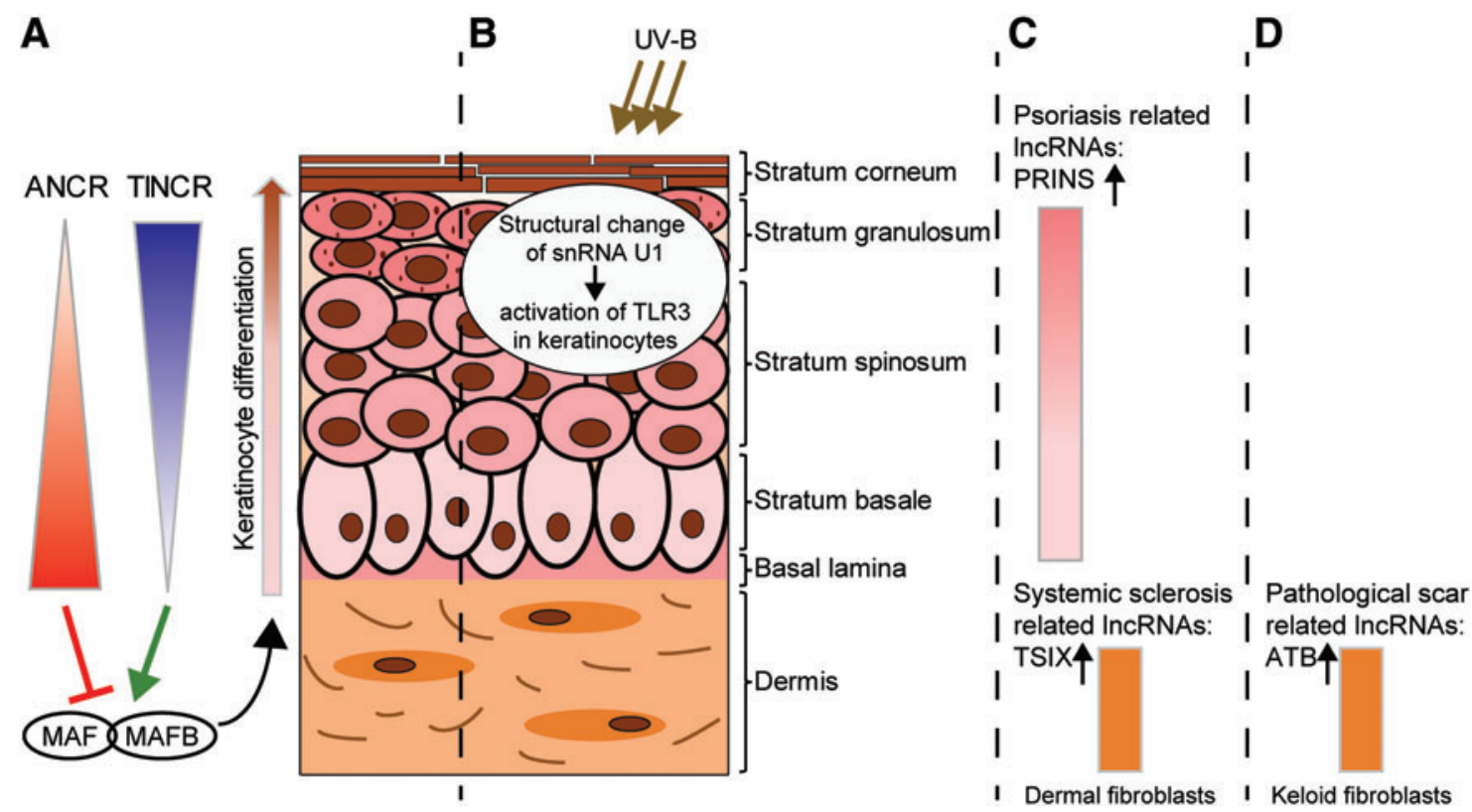

Figure 3. IncRNAs in epidermal homeostasis and skin diseases. (A) Schematic of human skin. ANCR is the most highly expressed in the basal layer keratinocytes, which is important to maintain the undifferentiated state in the epidermal progenitor compartment. TINCR is the most abundant in the differentiated layers and regulates the differentiation of keratinocytes. Both act upstream of MAF and MAFB, which are transcription factors that are both sufficient and essential for epidermal differentiation. (B) On injury with UV-B, snRNA U1 undergoes a structural change and activates TLR3 in keratinocytes. (C) A set of IncRNAs has been identified to be differentially expressed in psoriasis skin, compared with healthy skin. PRINS is one of the IncRNAs upregulated in psoriasis skin. TSIX regulates the stability of collagen I mRNA and is overexpressed in dermal fibroblasts from patients with systemic sclerosis. (D) The IncRNA ATB, which regulates TGF- $\beta$ signaling, is strongly expressed in keloid fibroblasts. ANCR, anti-differentiation ncRNA; PRINS, psoriasis susceptibilityrelated RNA gene induced by stress; TGF, transforming growth factor; TINCR, tissue differentiation-inducing non-coding RNA; TLR, toll-like receptor; UV, ultraviolet. To see this illustration in color, the reader is referred to the web version of this article at www.liebertpub.com/wound

healthy and diseased skin have been generated. For example, using RNA deep sequencing, a unique lncRNA expression profile has been recently identified in the psoriasis skin compared with the healthy skin. ${ }^{120,121}$ The abnormal expression of lncRNAs in psoriasis was reverted after successful treatment with adalimumab, a humanized antibody against TNF- $\alpha .{ }^{121}$ Interestingly, bioinformatics analysis revealed that many of these psoriasis-related lncRNAs were co-expressed with genes with immune functions, suggesting that these lncRNAs may function as immune regulators, contributing to the pathogenesis of psoriasis. ${ }^{120}$ Recently, in dermal fibroblasts from patients with systemic sclerosis, an lncRNA, the reverse of $\mathrm{X}$-inactive specific transcript (TSIX), was found to be overexpressed, which was induced by TGF- $\beta$ signaling ${ }^{122}$ (Fig. 3). Depletion of TSIX strongly reduced the stability of collagen I mRNA, indicating that TSIX overexpression contributes to the constitutive upregulation of collagen in systemic sclerosis dermal fibroblasts. ${ }^{122}$

Although the role of lncRNAs in normal skin wound healing remains unexplored, emerging evidences have linked lncRNAs to pathological scars (Fig. 3). By microarray analysis, Liang et al. iden- tified more than 2,500 lncRNAs to be differentially expressed in keloid tissue compared with the normal human skin. ${ }^{123}$ In keloids, TGF- $\beta$ signaling has been demonstrated to be highly activated. ${ }^{124}$ In line with this, in keloid fibroblasts a TGF- $\beta$ induced lncRNA, lncRNA-ATB, was shown to sequester miR-200c away from its target mRNA, ZNF217, which is a transcriptional activator of TGF- $\beta$. This leads to increased ZNF217 expression and autocrine secretion of TGF- $\beta .{ }^{125}$ In addition, $\mathrm{Li}$ et al. identified almost 1,900 lncRNAs and 900 mRNAs to be differentially expressed in regressive scars compared with mature scars. ${ }^{126}$ Gene ontology and pathway analysis showed that many processes over-represented in regressive scars were related to immune response. ${ }^{126}$

The published research data regarding the role of lncRNAs in skin biology and diseases strongly support the potential role of lncRNAs in wound repair, although the experimental evidence is still scant. Investigating the expression and function of lncRNAs will open a new avenue for understanding the molecular mechanisms of wound healing and may identify novel therapeutic targets for wound complications. 


\section{SUMMARY}

The vast majority of the human genome consists of ncRNAs; however, the knowledge about their expression and function is meager compared with what we know about protein-coding genes. Intensive studies in the past decades have revealed that different species of ncRNAs play important roles in both physiological and pathological conditions. In this review, we summarized the recent research progress about the role of ncRNAs, especially miRNAs and lncRNAs, in skin wound repair, which adds new layers of complexity to our understanding of normal skin wound healing as well as to the pathogenesis of wound disorders, e.g., chronic wounds and pathological scars. Because their expression is subjected to extremely precise regulation, which is dependent on cell/tissue type or disease ${ }^{120,127}$ both miRNAs and lncRNAs have a high potential to serve as a novel class of biomarkers for risk assessment, diagnosis, prognosis, and monitoring of treatment effects. Notably, miRNAs have been found to exist in biofluids, e.g., blood, in very stable forms, and reflecting various physiological and pathological status, which increase the likelihood of the development of miRNA-based biomarkers. ${ }^{128}$ To date, there are no specific and sensitive biomarkers to assess wounds to guide therapy and to aid in the timing of wound closure. ${ }^{129}$ Development of ncRNAbased biomarkers would be an interesting and important avenue for wound-healing research. For instance, a clinical trial is currently ongoing to test whether miR-210 may serve as a molecular marker in chronic wounds to predict healing outcomes. ${ }^{130}$

miRNAs are powerful gene regulators that often target several genes within the same gene network. Modulation of a single miRNA may result in a strong effect due to multiple gene expression changes in the same pathway. Therefore, miRNA-based treatment may be more effective compared with traditional drugs targeting single proteins. ${ }^{17}$ With the identification of miRNAs that are important for diseases and the development of methods modulating miRNA function in vivo, several miRNA-based treatments have entered clinical trials and exhibit very promising therapeutic effects. ${ }^{17}$ To date, increasing numbers of miRNAs have been identified that are critical for skin wound repair, and it is important to evaluate their therapeutic potentials for skin wounds. If successful, this will lead to a novel therapeutic approach for those wound complications, which are difficult to treat to date. In comparison to
miRNAs, we know even less about the role of lncRNAs in skin wound healing. Investigation of lncRNAs will increase our understanding about skin wound repair, which may open up a broad new field of potential biomarkers and therapeutic targets.

\section{ACKNOWLEDGMENTS AND FUNDING SOURCES}

This work was supported by the Swedish Research Council (Vetenskapsradet, Dnr. 2013-03085, 2015-06246), Ragnar Söderbergs Foundation (M31/ 15), Hedlunds Foundation, Welander and Finsens Foundations (Hudfonden), Åke Wibergs Foundation, Jeanssons Foundation, Swedish Psoriasis Foundation, and Karolinska Institutet.

\section{AUTHOR DISCLOSURES AND GHOSTWRITING}

The authors have no competing financial interests. The content of this article was expressly written by the authors listed. No ghostwriters were involved in the writing of this article.

\section{ABOUT THE AUTHORS}

Eva K. Herter, PhD, is a postdoctoral researcher at Karolinska Institutet. She is working with ncRNAs in skin wound healing. Ning Xu Landén, PhD, is an assistant professor at Karolinska Institutet. She is the principal investigator leading a research team working on regulatory RNAs and skin wound healing. The goal of her research is to develop RNA-based therapy, improving current wound treatments. 


\section{REFERENCES}

1. Reinke JM, Sorg H. Wound repair and regeneration. Eur Surg Res 2012;49:35-43.

2. Sen CK, Gordillo GM, Roy S, et al. Human skin wounds: a major and snowballing threat to public health and the economy. Wound Repair Regen 2009;17:763-771.

3. Gottrup F, Holstein P, Jorgensen B, Lohmann M, Karlsmar T. A new concept of a multidisciplinary wound healing center and a national expert function of wound healing. Arch Surg 2001;136:765-772.

4. Phillips T, Stanton B, Provan A, Lew R. A study of the impact of leg ulcers on quality of life: Financial, social, and psychologic implications. J Am Acad Dermatol 1994;31:49-53.

5. Escandon J, Vivas AC, Tang J, Rowland KJ, Kirsner RS. High mortality in patients with chronic wounds. Wound Repair Regen 2011;19:526-528.

6. Iversen MM, Tell GS, Riise T, et al. History of foot ulcer increases mortality among individuals with diabetes: ten-year follow-up of the NordTrondelag Health Study, Norway. Diabetes Care 2009:32:2193-2199.

7. Eming SA, Martin P, Tomic-Canic M. Wound repair and regeneration: Mechanisms, signaling, and translation. Sci Transl Med 2014;6:265sr266.

8. Consortium EP. An integrated encyclopedia of DNA elements in the human genome. Nature 2012;489:57-74.

9. Fatica A, Bozzoni I. Long non-coding RNAs: New players in cell differentiation and development. Nat Rev Genet 2014;15:7-21.

10. Mercer TR, Dinger ME, Mattick JS. Long noncoding RNAs: Insights into functions. Nat Rev Genet 2009;10:155-159.

11. Mattick JS, Makunin IV. Non-coding RNA. Hum Mol Genet 2006;15 Spec No 1:R17-R29.

12. Tollervey $D$, Kiss $T$. Function and synthesis of small nucleolar RNAs. Curr Opin Cell Biol 1997; 9:337-342.

13. Wassarman DA, Steitz JA. Interactions of small nuclear RNA's with precursor messenger RNA during in vitro splicing. Science 1992;257:1918-1925.

14. Lee RC, Feinbaum RL, Ambros V. The $c$ elegans heterochronic gene lin-4 encodes small RNAs with antisense complementary to lin-14. Cell 1993;75:843-854.

15. Ha M, Kim VN. Regulation of microRNA biogenesis. Nat Rev Mol Cell Biol 2014;15:509-524.

16. Friedman RC, Farh KK, Burge CB, Bartel DP. Most mammalian mRNAs are conserved targets of microRNAs. Genome Res 2009;19:92-105.

17. van Rooij E, Kauppinen S. Development of microRNA therapeutics is coming of age. EMBO Mol Med 2014;6:851-864.

18. Iyer MK, Niknafs YS, Malik R, et al. The landscape of long noncoding RNAs in the human transcriptome. Nat Genet 2015;47:199-208.
19. Milligan MJ, Lipovich L. Pseudogene-derived IncRNAs: emerging regulators of gene expression. Front Genet 2014;5:476.

20. Peschansky VJ, Wahlestedt C. Non-coding RNAs as direct and indirect modulators of epigenetic regulation. Epigenetics 2014;9:3-12.

21. Derrien T, Johnson R, Bussotti G, et al. The GENCODE v7 catalog of human long noncoding RNAs: analysis of their gene structure, evolution, and expression. Genome Res 2012;22:1775-1789.

22. Wilusz JE, Sunwoo H, Spector DL. Long noncoding RNAs: functional surprises from the RNA world. Genes Dev 2009;23:1494-1504.

23. Meisgen $F$, Xu Landen N, Wang A, et al. MiR146a negatively regulates TLR2-induced inflammatory responses in keratinocytes. J Invest Dermatol 2014;134:1931-1940.

24. Ghatak S, Chan YC, Khanna S, et al. Barrier function of the repaired skin is disrupted following arrest of dicer in keratinocytes. Mol Ther 2015;23:1201-1210.

25. Strodtbeck F. Physiology of wound healing. Newborn Infant Nurs Rev 2001;1:43-52.

26. Sinno H, Prakash S. Complements and the wound healing cascade: an updated review. Plast Surg Int 2013;2013:146764.

27. Wilgus TA, Roy S, McDaniel JC. Neutrophils and wound repair: Positive actions and negative reactions. Adv Wound Care (New Rochelle) 2013; 2:379-388.

28. Galli SJ, Borregaard N, Wynn TA. Phenotypic and functional plasticity of cells of innate immunity: macrophages, mast cells and neutrophils. Nat Immunol 2011;12:1035-1044.

29. Mosser DM. The many faces of macrophage activation. J Leukoc Biol 2003;73:209-212.

30. Brancato SK, Albina JE. Wound macrophages as key regulators of repair: origin, phenotype, and function. Am J Pathol 2011;178:19-25.

31. Fadok VA, Bratton DL, Konowal A, et al. Macrophages that have ingested apoptotic cells in vitro inhibit proinflammatory cytokine production through autocrine/paracrine mechanisms involving TGF-beta, PGE2, and PAF. J Clin Invest 1998;101:890-898.

32. Landen NX, Li D, Stahle M. Transition from inflammation to proliferation: a critical step during wound healing. Cell Mol Life Sci 2016;73:3861-3865.

33. Essandoh K, Li Y, Huo J, Fan GC. MiRNAmediated macrophage polarization and its potential role in the regulation of inflammatory response. Shock 2016;46:122-131.

34. Taganov KD, Boldin MP, Chang KJ, Baltimore D. NF-kappaB-dependent induction of microRNA miR-146, an inhibitor targeted to signaling proteins of innate immune responses. Proc Natl Acad Sci U S A 2006;103:12481-12486.

35. Tili E, Michaille JJ, Cimino A, et al. Modulation of miR-155 and miR-125b levels following lipo-
polysaccharide/TNF-alpha stimulation and their possible roles in regulating the response to endotoxin shock. J Immunol 2007;179:5082-5089.

36. Meisgen F, Xu Landen N, Bouez C, et al. Activation of toll-like receptors alters the microRNA expression profile of keratinocytes. Exp Dermatol 2014;23:281-283.

37. Hou J, Wang P, Lin L, et al. MicroRNA-146a feedback inhibits RIG-I-dependent type I IFN production in macrophages by targeting TRAF6, IRAK1, and IRAK2. J Immunol 2009;183:2150-2158.

38. Li D, Wang A, Liu X, et al. MicroRNA-132 enhances transition from inflammation to proliferation during wound healing. J Clin Invest 2015; 125:3008-3026.

39. $X u J, W u W$, Zhang $L$, et al. The role of microRNA-146a in the pathogenesis of the diabetic wound-healing impairment: correction with mesenchymal stem cell treatment. Diabetes 2012;61:2906-2912.

40. Faraoni I, Antonetti FR, Cardone J, Bonmassar E. miR-155 gene: a typical multifunctional microRNA. Biochim Biophys Acta 2009;1792:497-505.

41. van Solingen C, Araldi E, Chamorro-Jorganes A, Fernandez-Hernando C, Suarez Y. Improved repair of dermal wounds in mice lacking microRNA-155. J Cell Mol Med 2014;18:1104-1112.

42. Yang LL, Liu JQ, Bai XZ, et al. Acute downregulation of miR-155 at wound sites leads to a reduced fibrosis through attenuating inflammatory response. Biochem Biophys Res Commun 2014:453:153-159.

43. Nahid MA, Yao B, Dominguez-Gutierrez PR, et al. Regulation of TLR2-mediated tolerance and cross-tolerance through IRAK4 modulation by miR-132 and miR-212. J Immunol 2013;190: 1250-1263.

44. Liu F, Li $Y$, Jiang $R$, et al. miR-132 inhibits lipopolysaccharide-induced inflammation in alveolar macrophages by the cholinergic anti-inflammatory pathway. Exp Lung Res 2015;41:261-269.

45. Larsen MT, Hother C, Hager M, et al. MicroRNA profiling in human neutrophils during bone marrow granulopoiesis and in vivo exudation. PLoS One 2013;8:e58454.

46. Huang $Y$, Lei $Y$, Zhang $H$, et al. MicroRNA regulation of STAT4 protein expression: rapid and sensitive modulation of IL-12 signaling in human natural killer cells. Blood 2011;118: 6793-6802.

47. Shaked I, Meerson A, Wolf $Y$, et al. MicroRNA132 potentiates cholinergic anti-inflammatory signaling by targeting acetylcholinesterase. Immunity 2009;31:965-973.

48. Das A, Ganesh K, Khanna S, Sen CK, Roy S. Engulfment of apoptotic cells by macrophages: a role of microRNA-21 in the resolution of wound inflammation. J Immunol 2014;192:1120-1129. 
49. Recchiuti A, Krishnamoorthy S, Fredman G, Chiang N, Serhan CN. MicroRNAs in resolution of acute inflammation: identification of novel resolvin D1miRNA circuits. FASEB J 2011;25:544-560.

50. Androulidaki A, lliopoulos D, Arranz A, et al. The kinase Akt1 controls macrophage response to lipopolysaccharide by regulating microRNAs. Immunity 2009;31:220-231.

51. Murphy AJ, Guyre PM, Pioli PA. Estradiol suppresses NF-kappa B activation through coordinated regulation of let-7a and miR-125b in primary human macrophages. J Immunol 2010;184:5029-5037.

52. Chaudhuri AA, So AY, Sinha N, et al. MicroRNA125b potentiates macrophage activation. J Immunol 2011;187:5062-5068.

53. Chen $\mathrm{Q}$, Wang $\mathrm{H}$, Liu $\mathrm{Y}$, et al. Inducible microRNA-223 down-regulation promotes TLRtriggered IL-6 and IL-1beta production in macrophages by targeting STAT3. PLoS One 2012; 7:e42971.

54. Lau K, Paus R, Tiede S, Day P, Bayat A. Exploring the role of stem cells in cutaneous wound healing. Exp Dermatol 2009;18:921-933.

55. Miller SJ, Burke EM, Rader MD, Coulombe PA Lavker RM. Re-epithelialization of porcine skin by the sweat apparatus. J Invest Dermatol 1998;110:13-19

56. Barrientos S, Stojadinovic 0, Golinko MS, Brem $\mathrm{H}$, Tomic-Canic M. Growth factors and cytokines in wound healing. Wound Repair Regen 2008; 16:585-601.

57. Wang $T$, Feng $Y$, Sun $H$, et al. miR-21 regulates skin wound healing by targeting multiple aspects of the healing process. Am J Pathol 2012;181: 1911-1920.

58. Yang X, Wang J, Guo SL, et al. miR-21 promotes keratinocyte migration and re-epithelialization during wound healing. Int J Biol Sci 2011;7:685-690.

59. Madhyastha R, Madhyastha $H$, Nakajima Y, Omura $S$, Maruyama M. MicroRNA signature in diabetic wound healing: promotive role of miR-21 in fibroblast migration. Int Wound J 2012;9:355-361.

60. Pastar I, Khan AA, Stojadinovic 0, et al. Induction of specific microRNAs inhibits cutaneous wound healing. J Biol Chem 2012;287:29324-29335.

61. Li D, Li X, Wang A, et al. MicroRNA-31 Promotes skin wound healing by enhancing keratinocyte proliferation and migration. $J$ Invest Dermatol 2015:135:1676-1685

62. Sundaram GM, Common JE, Gopal FE, et al. 'See-saw' expression of microRNA-198 and FSTL1 from a single transcript in wound healing. Nature 2013:495:103-106.

63. Wang J, Dan G, Shangguan T, et al. miR-198 represses the proliferation of $\mathrm{HaCaT}$ cells by targeting cyclin D2. Int J Mol Sci 2015;16:17018-17028.

64. Jin $Y$, Tymen SD, Chen D, et al. MicroRNA-99 family targets AKT/mTOR signaling pathway in dermal wound healing. PLoS One 2013;8:e64434.
65. Biswas S, Roy S, Banerjee J, et al. Hypoxia inducible microRNA 210 attenuates keratinocyte proliferation and impairs closure in a murine model of ischemic wounds. Proc Natl Acad Sci U S A 2010;107:6976-6981.

66. Fasanaro P, D'Alessandra Y, Di Stefano V, et al MicroRNA-210 modulates endothelial cell response to hypoxia and inhibits the receptor tyrosine kinase ligand ephrin-A3. J Biol Chem 2008;283:15878-15883.

67. Ghatak S, Li J, Chan YC, et al. AntihypoxamiR functionalized gramicidin lipid nanoparticles rescue against ischemic memory improving cutaneous wound healing. Nanomedicine 2016;12:1827-1831.

68. Chan YC, Roy S, Huang Y, Khanna S, Sen CK. The microRNA miR-199a-5p down-regulation switches on wound angiogenesis by derepressing the v-ets erythroblastosis virus E26 oncogene homolog 1-matrix metalloproteinase-1 pathway. J Biol Chem 2012;287:41032-41043.

69. Chan YC, Khanna S, Roy S, Sen CK. miR-200b targets Ets-1 and is down-regulated by hypoxia to induce angiogenic response of endothelial cells. J Biol Chem 2011;286:2047-2056.

70. Chan YC, Roy S, Khanna S, Sen CK. Downregulation of endothelial microRNA-200b supports cutaneous wound angiogenesis by desilencing GATA binding protein 2 and vascular endothelial growth factor receptor 2. Arterioscler Thromb Vasc Biol 2012;32:1372-1382.

71. Anand S, Majeti BK, Acevedo LM, et al. MicroRNA132-mediated loss of p120RasGAP activates the endothelium to facilitate pathological angiogenesis. Nat Med 2010;16:909-914.

72. Chen Y, Gorski DH. Regulation of angiogenesis through a microRNA (miR-130a) that downregulates antiangiogenic homeobox genes $\mathrm{GAX}$ and HOXA5. Blood 2008;111:1217-1226.

73. Hinz B. Formation and function of the myofibroblast during tissue repair. J Invest Dermatol 2007; 127:526-537.

74. Xue M, Jackson CJ. Extracellular matrix reorganization during wound healing and its impact on abnormal scarring. Adv Wound Care (New Rochelle) 2015;4:119-136.

75. Schilling JA. Wound healing. Surg Clin North Am 1976:56:859-874.

76. Lorenz HP, Lin RY, Longaker MT, Whitby DJ, Adzick NS. The fetal fibroblast: the effector cell of scarless fetal skin repair. Plast Reconstr Surg 1995;96:1251-1261.

77. Li P, Liu P, Xiong RP, et al. Ski, a modulator of wound healing and scar formation in the rat skin and rabbit ear. J Pathol 2011;223:659-671.

78. Xie C, Shi K, Zhang X, Zhao J, Yu J. MiR-1908 promotes scar formation post-burn wound healing by suppressing Ski-mediated inflammation and fibroblast proliferation. Cell Tissue Res 2016;366:371-380.

79. Cushing L, Kuang PP, Qian J, et al. miR-29 is a major regulator of genes associated with pul- monary fibrosis. Am J Respir Cell Mol Biol 2011:45:287-294.

80. Liu Y, Taylor NE, Lu L, et al. Renal medullary microRNAs in Dahl salt-sensitive rats: miR-29b regulates several collagens and related genes. Hypertension 2010;55:974-982.

81. Roderburg C, Urban GW, Bettermann K, et al. Micro-RNA profiling reveals a role for miR-29 in human and murine liver fibrosis. Hepatology 2011;53:209-218.

82. Monaghan M, Browne S, Schenke-Layland K, Pandit A. A collagen-based scaffold delivering exogenous microrna-29B to modulate extracellular matrix remodeling. Mol Ther 2014;22:786-796.

83. Gauglitz GG, Korting HC, Pavicic T, Ruzicka T, Jeschke MG. Hypertrophic scarring and keloids: pathomechanisms and current and emerging treatment strategies. Mol Med 2011; 17:113-125.

84. Gras C, Ratuszny D, Hadamitzky C, et al. miR-145 contributes to hypertrophic scarring of the skin by inducing myofibroblast activity. Mol Med 2015;21:296-304.

85. Mu S, Kang B, Zeng W, Sun Y, Yang F MicroRNA-143-3p inhibits hyperplastic scar formation by targeting connective tissue growth factor CTGF/CCN2 via the Akt/mTOR pathway. Mol Cell Biochem 2016;416:99-108.

86. Kwan P, Ding J, Tredget EE. MicroRNA 181b regulates decorin production by dermal fibroblasts and may be a potential therapy for hypertrophic scar. PLoS One 2015;10:e0123054.

87. Kashiyama K, Mitsutake N, Matsuse M, et al miR-196a downregulation increases the expression of type I and III collagens in keloid fibroblasts. J Invest Dermatol 2012;132:1597-1604.

88. Zhang GY, Wu LC, Liao T, et al. A novel regulatory function for miR-29a in keloid fibrogenesis. Clin Exp Dermatol 2016;41:341-345.

89. Li C, Zhu HY, Bai WD, et al. MiR-10a and miR181c regulate collagen type I generation in hypertrophic scars by targeting PAl-1 and uPA. FEBS Lett 2015;589:380-389.

90. Li G, Zhou R, Zhang Q, et al. Fibroproliferative effect of microRNA-21 in hypertrophic scar derived fibroblasts. Exp Cell Res 2016;345:93-99.

91. Li P, He QY, Luo CQ. Overexpression of miR-200b inhibits the cell proliferation and promotes ap optosis of human hypertrophic scar fibroblasts in vitro. J Dermatol 2014;41:903-911.

92. Liu Y, Wang X, Yang D, Xiao Z, Chen X. MicroRNA21 affects proliferation and apoptosis by regulating expression of PTEN in human keloid fibroblasts. Plast Reconstr Surg 2014;134:561e-573e.

93. Wu ZY, Lu L, Liang J, et al. Keloid microRNA expression analysis and the influence of miR199a-5p on the proliferation of keloid fibroblasts. Genet Mol Res 2014;13:2727-2738.

94. Zhou R, Zhang Q, Zhang Y, Fu S, Wang C Aberrant miR-21 and miR-200b expression and 
its pro-fibrotic potential in hypertrophic scars. Exp Cell Res 2015;339:360-366.

95. Zhu HY, Li C, Bai WD, et al. MicroRNA-21 regulates hTERT via PTEN in hypertrophic scar fibroblasts. PLoS One 2014;9:e97114.

96. Demidova-Rice TN, Hamblin MR, Herman IM. Acute and impaired wound healing: pathophysiology and current methods for drug delivery, part 2: role of growth factors in normal and pathological wound healing: Therapeutic potential and methods of delivery. Adv Skin Wound Care 2012;25:349-370.

97. Bodnar RJ. Chemokine regulation of angiogenesis during wound healing. Adv Wound Care (New Rochelle) 2015;4:641-650.

98. Amin N, Doupis J. Diabetic foot disease: From the evaluation of the "foot at risk" to the novel diabetic ulcer treatment modalities. World $\mathrm{J}$ Diabetes 2016;7:153-164.

99. Naves CC. The diabetic foot: A historical overview and gaps in current treatment. Adv Wound Care (New Rochelle) 2016;5:191-197.

100. Liu YF, Ding M, Liu DW, et al. MicroRNA profiling in cutaneous wounds of diabetic rats. Genet Mol Res 2015;14:9614-9625.

101. Icli B, Nabzdyk CS, Lujan-Hernandez J, et al. Regulation of impaired angiogenesis in diabetic dermal wound healing by microRNA-26a. J Mol Cell Cardiol 2016;91:151-159.

102. Jiang L, Zhu Z-M, Gao F, et al. Bone marrow mesenchymal stem cells accelerate wound healing in diabetic mice via inhibiting the expression of microRNA-155 to up-regulate Sirt1 in endothelial cells. Int J Clin Exp Pathol 2016;9:2980-2988.

103. Xu J, Zgheib C, Hu J, et al. The role of microRNA$15 \mathrm{~b}$ in the impaired angiogenesis in diabetic wounds. Wound Repair Regen 2014;22:671-677.

104. Wang JM, Tao J, Chen DD, et al. MicroRNA miR-27b rescues bone marrow-derived angiogenic cell function and accelerates wound healing in type 2 diabetes mellitus. Arterioscler Thromb Vasc Biol 2014;34:99-109.

105. Dhall S, Do DC, Garcia M, et al. Generating and reversing chronic wounds in diabetic mice by manipulating wound redox parameters. J Diabetes Res 2014;2014:562625.

106. Creemers EE, Tijsen AJ, Pinto YM. Circulating microRNAs: novel biomarkers and extracellular communicators in cardiovascular disease? Circ Res 2012;110:483-495.

107. Dangwal S, Stratmann B, Bang C, et al. Impairment of wound healing in patients with type 2 diabetes mellitus influences circulating microRNA patterns via inflammatory cytokines. Arterioscler Thromb Vasc Biol 2015;35:1480-1488.

108. Zhao G, Usui ML, Lippman SI, et al. Biofilms and inflammation in chronic wounds. Adv Wound Care (New Rochelle) 2013;2:389-399.

109. Roy S, Elgharably H, Sinha M, et al. Mixedspecies biofilm compromises wound healing by disrupting epidermal barrier function. $\mathrm{J}$ Pathol 2014;233:331-343.

110. Quinn JJ, Chang HY. Unique features of long non-coding RNA biogenesis and function. Nat Rev Genet 2016;17:47-62.

111. Kretz M, Siprashvili Z, Chu C, et al. Control of somatic tissue differentiation by the long noncoding RNA TINCR. Nature 2013;493:231-235.

112. Kretz M, Webster DE, Flockhart RJ, et al. Suppression of progenitor differentiation requires the long noncoding RNA ANCR. Genes Dev 2012;26:338-343.

113. Lopez-Pajares V, Ou K, Zhang J, et al. A LncRNAMAF:MAFB transcription factor network regulates epidermal differentiation. Dev Cell 2015;32:693-706.

114. Bernard JJ, Cowing-Zitron C, Nakatsuji T, et al. Ultraviolet radiation damages self noncoding RNA and is detected by TLR3. Nat Med 2012; 18:1286-1290.

115. Borkowski AW, Park K, Uchida Y, Gallo RL. Activation of TLR3 in keratinocytes increases expres sion of genes involved in formation of the epidermis, lipid accumulation, and epidermal organelles. J Invest Dermatol 2013;133:2031-2040.

116. Lai Y, Di Nardo A, Nakatsuji T, et al. Commensal bacteria regulate Toll-like receptor 3-dependent inflammation after skin injury. Nat Med 2009; 15:1377-1382.

117. Morhenn VB, Nelson TE, Gruol DL. The rate of wound healing is increased in psoriasis. $J$ Dermatol Sci 2013;72:87-92.

118. Sonkoly E, Bata-Csorgo Z, Pivarcsi A, et al. Identification and characterization of a novel, psoriasis susceptibility-related noncoding RNA gene, PRINS. J Biol Chem 2005;280:24159-24167.

119. Szell M, Danis J, Bata-Csorgo Z, Kemeny L. PRINS, a primate-specific long non-coding RNA, plays a role in the keratinocyte stress response and psoriasis pathogenesis. Pflugers Arch 2016; 468:935-943.

120. Tsoi LC, lyer MK, Stuart PE, et al. Analysis of long non-coding RNAs highlights tissue-specific expression patterns and epigenetic profiles in normal and psoriatic skin. Genome Biol 2015;16:24.

121. Gupta R, Ahn R, Lai K, et al. Landscape of long noncoding RNAs in psoriatic and healthy skin. $J$ Invest Dermatol 2016;136:603-609.

122. Wang Z, Jinnin M, Nakamura K, et al. Long noncoding RNA TSIX is upregulated in scleroderma dermal fibroblasts and controls collagen mRNA stabilization. Exp Dermatol 2016;25:131-136.

123. Liang $X$, Ma $L$, Long $X$, Wang $X$. LncRNA expression profiles and validation in keloid and normal skin tissue. Int J Oncol 2015;47:1829-1838.

124. Lee TY, Chin GS, Kim WJ, et al. Expression of transforming growth factor beta 1, 2, and 3 proteins in keloids. Ann Plast Surg 1999;43:179-184.

125. Zhu HY, Bai WD, Li C, et al. Knockdown of IncRNA-ATB suppresses autocrine secretion of TGF-beta2 by targeting ZNF217 via miR-200c in keloid fibroblasts. Sci Rep 2016;6:24728.
126. Li J, Long W, Li Q, et al. Distinct expression profiles of IncRNAs between regressive and mature scars. Cell Physiol Biochem 2015;35:663-675.

127. Cabili MN, Trapnell C, Goff L, et al. Integrative annotation of human large intergenic noncoding RNAs reveals global properties and specific subclasses. Genes Dev 2011;25:1915-1927.

128. Witwer KW. Circulating microRNA biomarker studies: pitfalls and potential solutions. Clin Chem 2015;61:56-63.

129. Hahm G, Glaser JJ, Elster EA. Biomarkers to predict wound healing: the future of complex war wound management. Plast Reconstr Surg 2011;127 Suppl 1:21S-26S.

130. Banerjee J, Sen CK. microRNA and wound healing. Adv Exp Med Biol 2015;888:291-305.

\section{Abbreviations and Acronyms}

ANCR $=$ anti-differentiation ncRNA

$\mathrm{ECM}=$ extracellular matrix

$\mathrm{EGF}=$ epidermal growth factor

$\mathrm{FGF}=$ fibroblast growth factor

FSTL1 = follistatin-like 1

GATA2: globin transcription factor binding protein 2

HOXA5 $=$ homeobox A5

HTS $=$ hypertrophic scar

IFN $=$ interferon

IGF1R = insulin-like growth factor 1 receptor

$\mathrm{IL}=$ interleukin

IRAK = interleukin 1 receptor-associated kinases

$\mathrm{KSRP}=\mathrm{KH}$-type splicing regulatory protein IncRNA = long non-coding RNA

LPS = lipopolysaccharide

MAPK $=$ mitogen-activated protein kinase

MEOX2 = mesenchyme homeobox2

$\mathrm{miR}=$ mature form of microRNA

miRNA $=$ microRNA

mRNA $=$ messenger RNA

ncRNA $=$ non-coding RNA

PDGF $=$ platelet-derived growth factor

PRINS $=$ psoriasis susceptibility-related RNA gene induced by stress

PTEN = phosphatase and tensin homolog

RASA $1=$ Ras P21 protein activator 1

$\mathrm{rRNA}=$ ribosomal RNA

snRNA $=$ small nuclear RNA

snoRNAs $=$ small nucleolar RNAs

STAT4 $=$ signal transducer and activator of transcription 4

TGF- $\beta=$ transforming growth factor beta

TINCR $=$ tissue differentiation-inducing non-coding RNA

$\mathrm{TLR}=$ toll-like receptor

TNF $=$ tumor necrosis factor

TRAF6 $=$ TNF receptor-associated factor 6

TSIX $=$ the reverse of $X$-inactive specific transcript

UTR $=$ untranslated region

$\mathrm{UV}=$ ultraviolet

VEGF $=$ vascular endothelial growth factor

VEGFR2 = vascular endothelial growth factor receptor 2

$\alpha$-SMA $=\alpha$-smooth muscle actin 